\title{
QUAL SERÁ O AMANHÃ DIGITAL E AS PERSPECTIVAS PARA O BRASIL DO FUTURO?
}

O mundo nunca se transformou tão rápido. A transformação digital avança sobre todas as áreas de nossas vidas e, mais do que nunca, precisamos estar prontos para criar oportunidades para que todos possam usufruir e contribuir com a economia digital.

A tecnologia, ou melhor dizendo, a inovação, ganhou um papel fundamental no processo de estímulo ao progresso para a sociedade, porém sem nunca excluir o papel das pessoas como parte crucial desse processo, agindo como especialistas, empreendedores e usuários, atuando como agentes de mudança.

Em 2019, ainda antes da pandemia, a Cisco conduziu um estudo sobre prontidão digital'. Os países mais bem posicionados, em um ranking de 141 participantes, foram aqueles que investiram (e investem) não só em tecnologia, mas na infraestrutura para essa tecnologia, em um ambiente propício para a inovação e para os negócios e, acima de tudo, em serviços essenciais para seus cidadãos e na capacitação desses cidadãos para um futuro cada vez mais digital. Nesse ranking, o Brasil ocupou a 67a posição no mundo e a nona da América Latina, sendo classificado no nível intermediário, ou seja, entre os países em aceleração digital, o que traz desafios e oportunidades que devem ser aproveitados. Enquanto o Brasil está bem posicionado em nível de investimento privado e em adoção de tecnologia, precisamos ainda percorrer um longo caminho quanto ao nosso ambiente de inovação para startups e na capacitação do nosso capital humano.

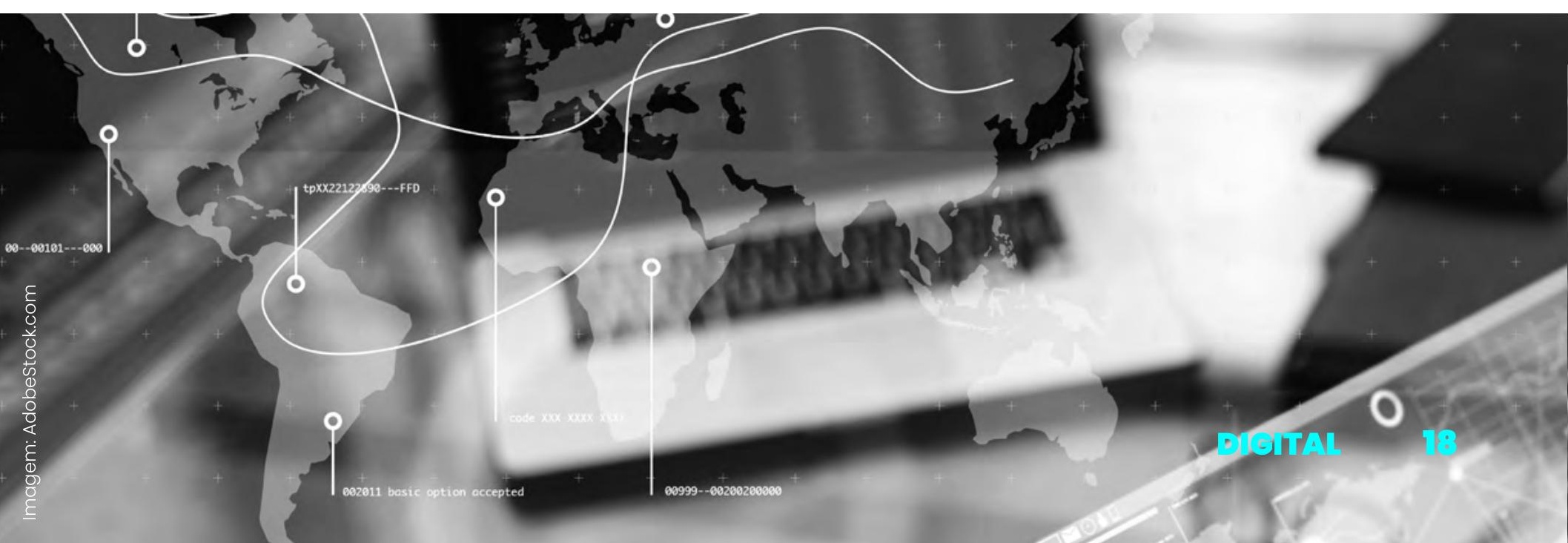


Ao longo dos últimos anos, empresas, instituições públicas e órgãos governamentais vinham passando por transformações digitais, porém essas mudanças aconteciam paulatinamente, ao sabor dos ventos de cada organização. Com a chegada da pandemia, todos tiveram de se adaptar. Não era mais possível se preparar para um futuro hipotético, o futuro estava acontecendo naquele momento! Na prática, nos três primeiros meses da pandemia, a transformação digital avançou três anos.

Em setembro de 2020, a Cisco lançou, com participação da Deloitte, o estudo 'Digitalização, Resiliência e Continuidade dos Negócios: o que aprendemos com a pandemia da COVID-19'2, trazendo uma análise sobre os impactos da pandemia na transformação digital. Verificamos que a pandemia forçou as organizações a acelerarem processos que já aconteciam e que essas iniciativas foram essenciais para garantir a continuidade dos negócios. Transições que estavam sendo realizadas em ritmo lento, visando um cronograma em médio prazo, tiveram que se acelerar a níveis nunca vistos, e novas plataformas digitais nasceram em um período recorde a partir deste processo.

\section{- legado desta transição foi uma economia e instituiçe̋es mais digitalizaders, à prova do futuro.}

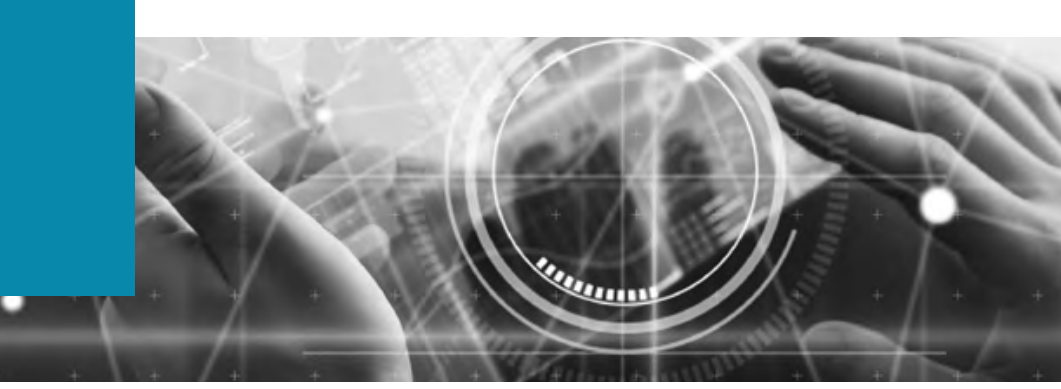

Um exemplo foi o setor da educação, historicamente rígido e resistente a inovações. As ofertas de cursos EAD cresceram, a regulamentação amadureceu e a tendência para um futuro pós-COVID-19 é que um modelo híbrido misture o EAD e as aulas presenciais em um sistema mais vantajoso para alunos e professores, com conteúdo mais rico e ao mesmo tempo mais objetivo.

Quando pensamos no panorama da prontidão digital no Brasil, muitas das organizações do país estão hoje em uma posição melhor do que estavam antes da pandemia da COVID-19.

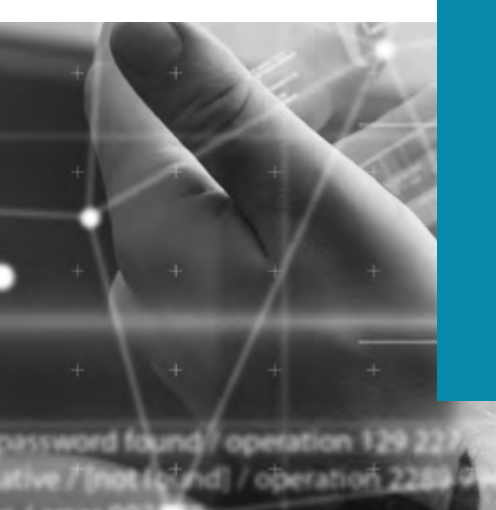

E parta melhorer ecd vez mais a nossa posiçc̃o entre as naçōes mais digitudizeders, inelusãoé uma necessidade urgente, pois não é possível follor em um futuro digital que não seja justoe inelusivo. Essa inelusão depende de dois pontos importentes:

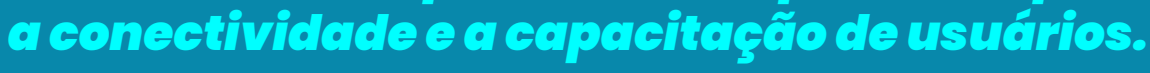

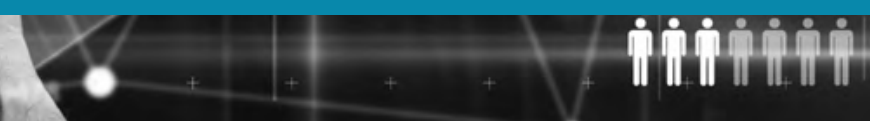


A conectividade ou o acesso à internet devem ser tratados como direitos fundamentais. A população precisa ter acesso à internet com conexão de banda larga para usufruir de serviços que vão desde o internet banking até educação e saúde a distância. E só o acesso não basta, as pessoas precisam de dispositivos para acessar a internet, sejam computadores, celulares ou tablets. A velocidade e a estabilidade de conexão também dependem da infraestrutura correta, e tecnologias como o $5 \mathrm{G}$ e o Wi-Fi6 são a chave para conectar os brasileiros à internet. Vale lembrar que muitas regiões rurais do país ainda não têm acesso à internet de banda larga, e essas tecnologias, com maior alcance, segurança e estabilidade, podem resolver muitos destes problemas. Com a entrada de novos fabricantes no mercado, a tendência é que essas tecnologias se tornem mais baratas e se disseminem, inclusive com um padrão aberto de $5 G$.

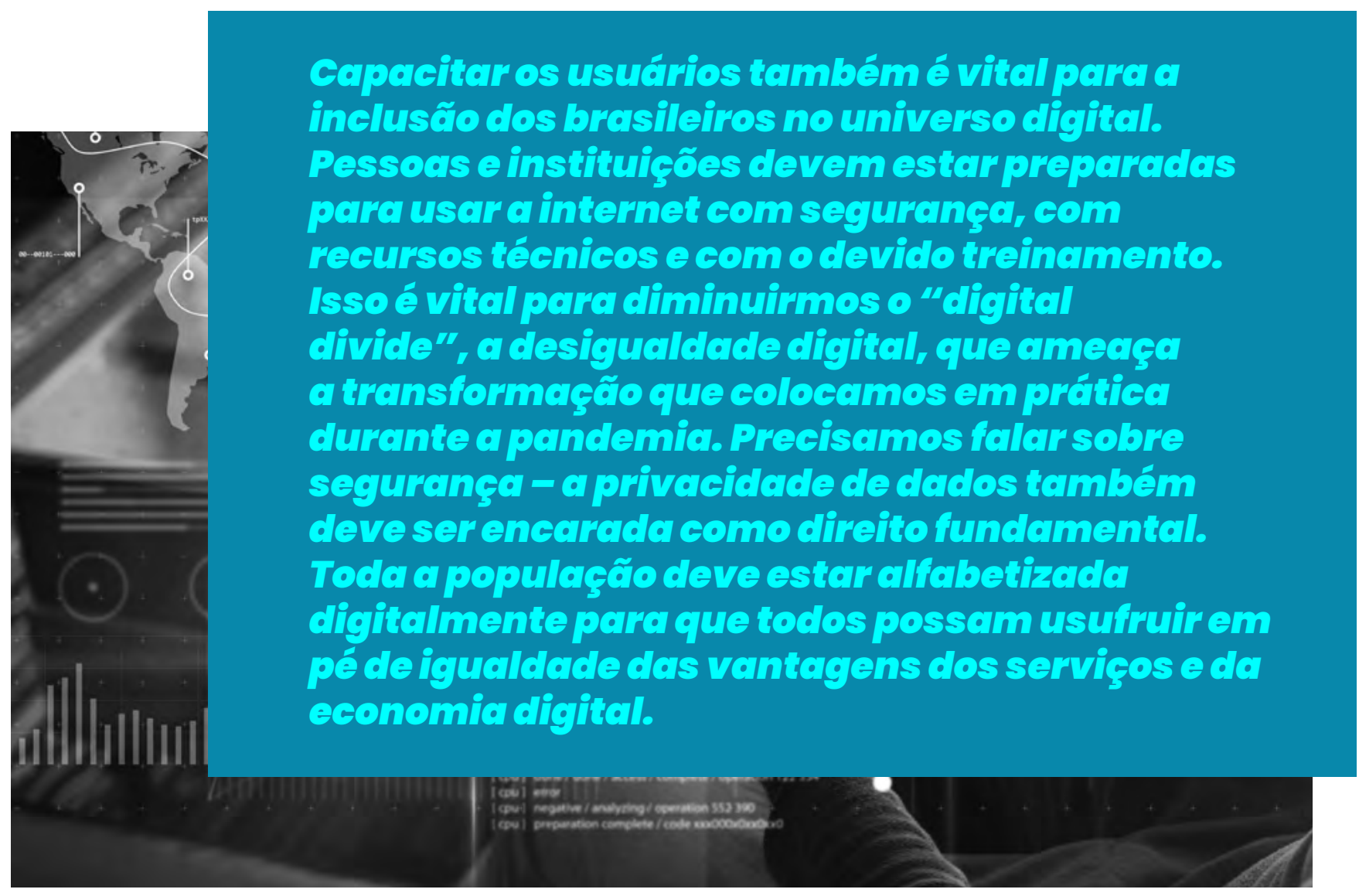

No estudo sobre digitalização do Brasil, verificamos que um dos grandes inibidores da digitalização do Brasil pós-COVID-19 ainda é a falta de capacitação, aliada à condição socioeconômica da população. As pessoas que não sabem usar novas tecnologias e não têm acesso a dispositivos ou a conexões adequadas para essas tecnologias acabam sendo deixadas para trás na busca por novas oportunidades de trabalho e educação. Cria-se, assim, um círculo vicioso, onde o abismo para aqueles digitalmente alfabetizados se amplia continuamente. O futuro do trabalho está sendo redesenhado neste momento e vai continuar mudando. 
Se quisermos digitallizar • Brasil, eabe a nós, socied ade e orgạnizeçöes públicas e privadas, oferecer oportunidades para que toda a populaçäo possa participar da nova economia e eriar a próxima geração de novas tecnologias.

Falo com coração e por experiência própria sobre a importância das oportunidades. Nasci em uma cidade pequena no Mato Grosso do Sul, chamada Batayporã, pelas mãos de uma parteira, numa casinha de madeira onde morávamos, e meus pais, meus heróis, somente foram à escola para aprender a ler e escrever. Cresci na periferia de São Paulo, estudando em escolas públicas e trabalhando desde os 12 anos de idade, e cheguei à vice-presidência da Cisco América Latina, não porque sou bom, mas porque tive oportunidade. Por isso, me considero um filho da oportunidade neste país, e acredito veemente que hoje a tecnologia pode ser o grande pilar de conexão entre as oportunidades e os talentos espalhados pelos cantões deste nosso lindo Brasil.

A Cisco está comprometida com a criação de mais oportunidades para um futuro inclusivo para todos, por meio de projetos como o Cisco Networking Academy, presente em 180 países, que capacita estudantes em áreas como

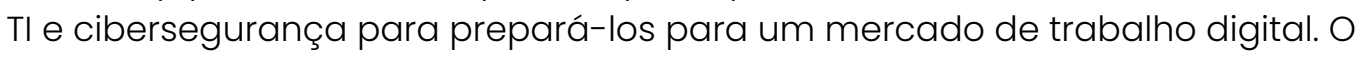
desenvolvimento de nosso país passa por isso, para que possamos desenvolver cada vez mais os talentos que estão espalhados pelo Brasil.

A prontidão digitel é construíde por pessods e orgarnizeçōes, umas transformando as outras. Essars

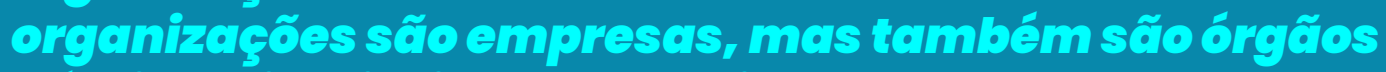
públices, instituiȩões de ensino, entre outras. Se trobelhalrmos juntos perra transformar descifios em oportunidedes, podemes trazer benefícios duradouros perre todos. Um futuro mais justo e inclusivo é possível e vemos construir esse cmahhõ com todos os bresileiros.

brasiteiros. 


\section{Løérei॰ Albuquerque}

Laércio Albuquerque é vice-presidente da Cisco América Latina, foi presidente e country manager da Cisco Brasil, responsável por liderar a estratégia da empresa para promover a inovação e a digitalização em todo o país.

Albuquerque trabalha no setor de tecnologia há mais de 30 anos e ocupou diversos cargos de liderança importantes no setor de tecnologia no Brasil e na América Latina. Ele começou sua carreira no BCN, Duratex e Pirelli. Ele se mudou para o mundo do desenvolvimento de software e depois para a CA Technologies, onde passou 20 anos até ingressar na Cisco no Brasil.

Albuquerque é graduado em Engenharia de Sistemas e Análise Gerencial pela FASP e possui MBA Executivo pelo Insper. 


\section{NOTASEREFERÊNCIAS}

1 https://www.cisco.com/c/m/en_us/about/corporate-social-responsibility/research-resources/digital-readiness-index.html\#/

2 https://www2.deloitte.com/br/pt/pages/strategy-operations/articles/analise-covid-setores.html 